Portland State University

PDXScholar

$1-1-2009$

\title{
Non-Linearity in Ecosystem Services: Temporal and Spatial Variability in Coastal Protection
}

\author{
Evamaria W. Koch \\ Edward Barbier \\ University of Wyoming \\ Brian R. Silliman \\ Denise J. Reed \\ Gerardo M. E. Perillo
}

See next page for additional authors

Follow this and additional works at: https://pdxscholar.library.pdx.edu/iss_pub

Part of the Sustainability Commons

Let us know how access to this document benefits you.

\begin{abstract}
Citation Details
Koch, Evamaria W., Edward B. Barbier, Brian R. Silliman, Denise J. Reed, Gerardo M. E. Perillo, Sally D. Hacker, Elise F. Granek, et al. 2007. Non-linearity in ecosystem services: temporal and spatial variability in coastal protection. Frontiers in Ecology and the Environment 7, no. 1:29-37.
\end{abstract}

This Article is brought to you for free and open access. It has been accepted for inclusion in Institute for Sustainable Solutions Publications and Presentations by an authorized administrator of PDXScholar. Please contact us if we can make this document more accessible: pdxscholar@pdx.edu. 


\section{Authors}

Evamaria W. Koch, Edward Barbier, Brian R. Silliman, Denise J. Reed, Gerardo M. E. Perillo, Sally D. Hacker, Elise F. Granek, Jurgenne H. Primavera, Nyawira Muthiga, Stephen Polasky, Benjamin S. Halpern,

Christopher J. Kennedy, Carrie V. Kappel, and Eric Wolanski 


\title{
Non-linearity in ecosystem services: temporal and spatial variability in coastal protection
}

\author{
Evamaria W Koch ${ }^{1 *}$, Edward B Barbier ${ }^{2}$, Brian R Silliman ${ }^{3}$, Denise J Reed ${ }^{4}$, Gerardo ME Perillo ${ }^{5}$, \\ Sally D Hacker ${ }^{6}$, Elise F Granek ${ }^{7}$, Jurgenne H Primavera ${ }^{8}$, Nyawira Muthiga ${ }^{9}$, Stephen Polasky ${ }^{10}$, \\ Benjamin S Halpern ${ }^{11}$, Christopher J Kenned ${ }^{2}$, Carrie V Kappel ${ }^{11}$, and Eric Wolanski ${ }^{12}$
}

\begin{abstract}
Natural processes tend to vary over time and space, as well as between species. The ecosystem services these natural processes provide are therefore also highly variable. It is often assumed that ecosystem services are provided linearly (unvaryingly, at a steady rate), but natural processes are characterized by thresholds and limiting functions. In this paper, we describe the variability observed in wave attenuation provided by marshes, mangroves, seagrasses, and coral reefs and therefore also in coastal protection. We calculate the economic consequences of assuming coastal protection to be linear. We suggest that, in order to refine ecosystem-based management practices, it is essential that natural variability and cumulative effects be considered in the valuation of ecosystem services.
\end{abstract}

Front Ecol Environ 2009; 7(1): 29-37, doi:10.1890/080126

$\mathrm{C}$ oastal ecosystems and the services they provide are under global siege. Climate change, nutrient loading, habitat degradation, food web alteration, and pollution all threaten their existence (Silliman et al. 2005; Orth et al. 2006; Halpern et al. 2008). Quantifying the economic values of services provided and incorporating these values into socioeconomic analyses is key to conserving these benefitgenerating ecosystems (NRC 2005; Hein et al. 2006). Currently, with few exceptions (eg Farnsworth 1998; Gaston 2000; Petersen et al. 2003; Dobson et al. 2006;

\section{In a nutshell:}

- Biological structures, such as mangrove forests, salt marshes, seagrass beds, and coral reefs attenuate waves and, as a result, provide coastal protection

- Although wave attenuation by biological structures can be highly variable over time and space, the ecosystem service of coastal protection is often assumed to change linearly (ie at a steady, unvarying rate)

- The value of storm protection provided by mangroves is very different if wave attenuation is assumed to be linear versus allowing it to vary over space and time

- Ecosystem-based management needs to include natural variability in calculations of ecosystem services provided when restoring coastal biotic structures for the purpose of improving coastal protection

${ }^{1}$ Horn Point Laboratory, University of Maryland Center for Environmental Science, Cambridge, MD*(koch@hpl.umces.edu); ${ }^{2}$ Department of Economics and Finance, University of Wyoming, Laramie, WY; ${ }^{3}$ Department of Biology, University of Florida, Gainesville, FL; ${ }^{4}$ Department of Earth and Environmental Sciences, University of New Orleans, New Orleans, LA; (continued on p37)
Aburto-Oropeza et al. 2008), a major underlying assumption of the valuation process is that the quantity of an ecosystem function varies linearly with independent characteristics and forcing variables, such as ecosystem size, seasonality, disturbance, and species interactions (Barbier et al. 2008a). However, the responses these independent variables generate in ecosystem functions are highly dynamic and non-linear across both space and time (Farnsworth 1998). For example, the function of wave attenuation by some seagrasses may be at its maximum during summer, when plants are reproducing (Chen et al. 2007), at medium levels in spring and fall, and non-existent during winter, when density and biomass are low. Furthermore, many ecological functions are likely to be characterized by a tendency to level off (ie asymptotic relationship) or change dramatically (ie ecological thresholds) over time and space, as is the case with certain ecological processes, such as population growth, predator functional responses, and species-area relationships (Cain et al. 2008). However, such non-linear relationships between ecological traits and ecosystem function, and ecosystem function and service delivery, have not been explored in depth, quantitatively or conceptually (except see Aburto-Oropeza et al. 2008).

Improvements in the understanding and quantification of non-linearities in ecosystem functions are likely to provide more realistic ecosystem service values and also to improve ecosystem-based management (EBM) practices (Barbier et al. 2008a). Current conservation decision making often takes into account only the qualitative benefits of ecosystems (eg whether or not a habitat is a fish nursery, rather than the value of the fisheries it maintains), as quantitative measures are generally unavailable. Barbier et al. (2008a) showed the consequences of trading 


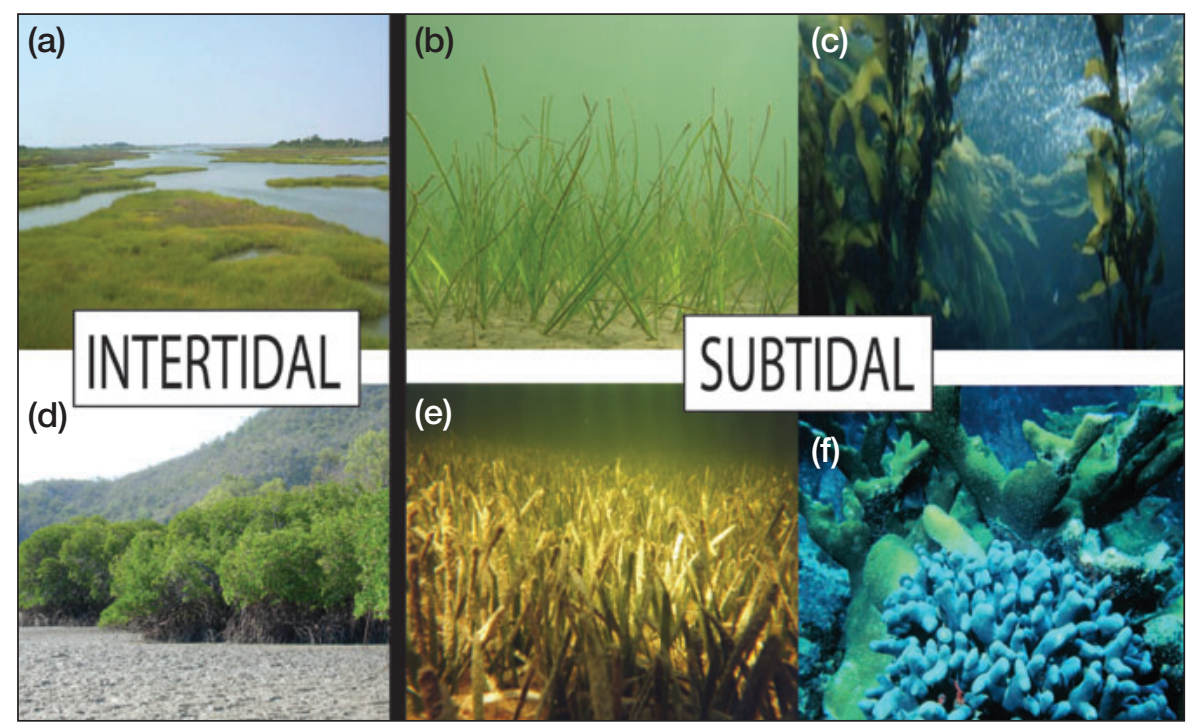

Figure 1. Examples of biotic structures that attenuate waves in temperate [(a) marshes, (b) seagrasses, and (c) kelp] and tropical [(d) mangroves, (e) seagrasses, and ( $f$ ) coral] intertidal and subtidal coastal areas. Corals often create sheltered conditions suitable for mangrove and seagrass growth; coral reefs therefore contribute directly and indirectly to coastal protection.

off multiple ecosystem services with and without accounting for non-linear functional responses to habitat size in mangrove systems. We build on this work and examine spatial and temporal heterogeneity in the ecosystem function of wave attenuation across a suite of coastal vegetated habitats (Figure 1 ). We then quantitatively evaluate how this heterogeneity leads to the nonlinear generation of storm protection services. We conclude by discussing the implications of non-linearity in ecosystem functions for management and conservation.

\section{How coastal habitats attenuate waves}

Wave attenuation is a function of the amount of plant and sedentary animal material obstructing the water column (Coops et al. 1996) and the bathymetry (measurements of water depth) of the area. Leaves, stems, and, in some cases, even roots of coastal vegetation are a source of friction to moving water (Massel et al. 1999), as is the reticulated structure of coral reefs (Madin and Connolly 2006). As a result, the biotic structures in coastal habitats affect the momentum of the water, leading to a reduction in current velocity and attenuation of wave energy (Koch et al. 2006). Although this ecosystem function may result in coastal protection, it cannot be assumed that the presence of coastal biotic structures leads to the full provision of this ecosystem service (Barbier et al. 2008b; Feagin 2008). For example, a sparse bed of the seagrass Ruppia maritima (eg early in the growing season) has been shown to contribute little to wave attenuation; the density of the bed needs to reach a threshold of 1000 shoots $\mathrm{m}^{-2}$ before this ecosystem function is observed (Chen et al. 2007).

Coastal biotic structures also contribute to wave attenthe edges of biotic structures receive the brunt of wave energy and, as a result, provide the most wave attenuation (Figure 2a) and the greatest value in terms of coastal protection. However, a narrow marginal fringe may not suffice to reduce wave energy to a level that will not damage coastal villages, especially during storm events. Shuto (1987) suggested that a 20 - or $100-\mathrm{m}$ wide mangrove belt would be necessary to protect against tsunami waves of 3 - and $6-\mathrm{m}$ in height, respectively. Likewise, Mazda et al. (1997) predicted that mangrove forests as wide as $1000 \mathrm{~m}$ might be required to reduce wave energy by $90 \%$, but that this was dependent on tree density rather than spatial extent of trees (Massel et al. 1999; Figure 2b). In very dense mangrove forests, full attenuation of wind-induced waves may occur within $30 \mathrm{~m}$ of the edge, while in low-density mangroves, such as those usually found at the edge of mangrove forests (Komiyama et al. 2008), much wider vegetated areas are required to obtain the same results (Massel et al. 1999).

Coastal protection also probably varies with latitude, as a result of the major differences in plant biomass and thus wave attenuation in different regions. For instance, mangrove aboveground biomass decreases from low to mid latitudes (between $0^{\circ}$ and $40^{\circ}$; Twilley et al. 1992; Komiyama et al. 2008), such that the highest wave attenuation is provided near the equator. For seagrasses, the opposite pattern seems to exist (Figure 2c). Aboveground biomass is lowest in the tropics in the summer (between $0^{\circ}$ and $10^{\circ}$ ), increases at mid latitudes (between $20^{\circ}$ and $30^{\circ}$ ), decreases again between latitudes $40^{\circ}$ and $50^{\circ}$, and is greatest at the highest latitude $\left(60^{\circ}\right.$; Duarte and Chiscano 1999). As a result, the ecosystem function of wave attenuation by seagrasses is expected to vary nonlinearly over latitudinal scales. Taken together, when considering wave attenuation processes over a broad 


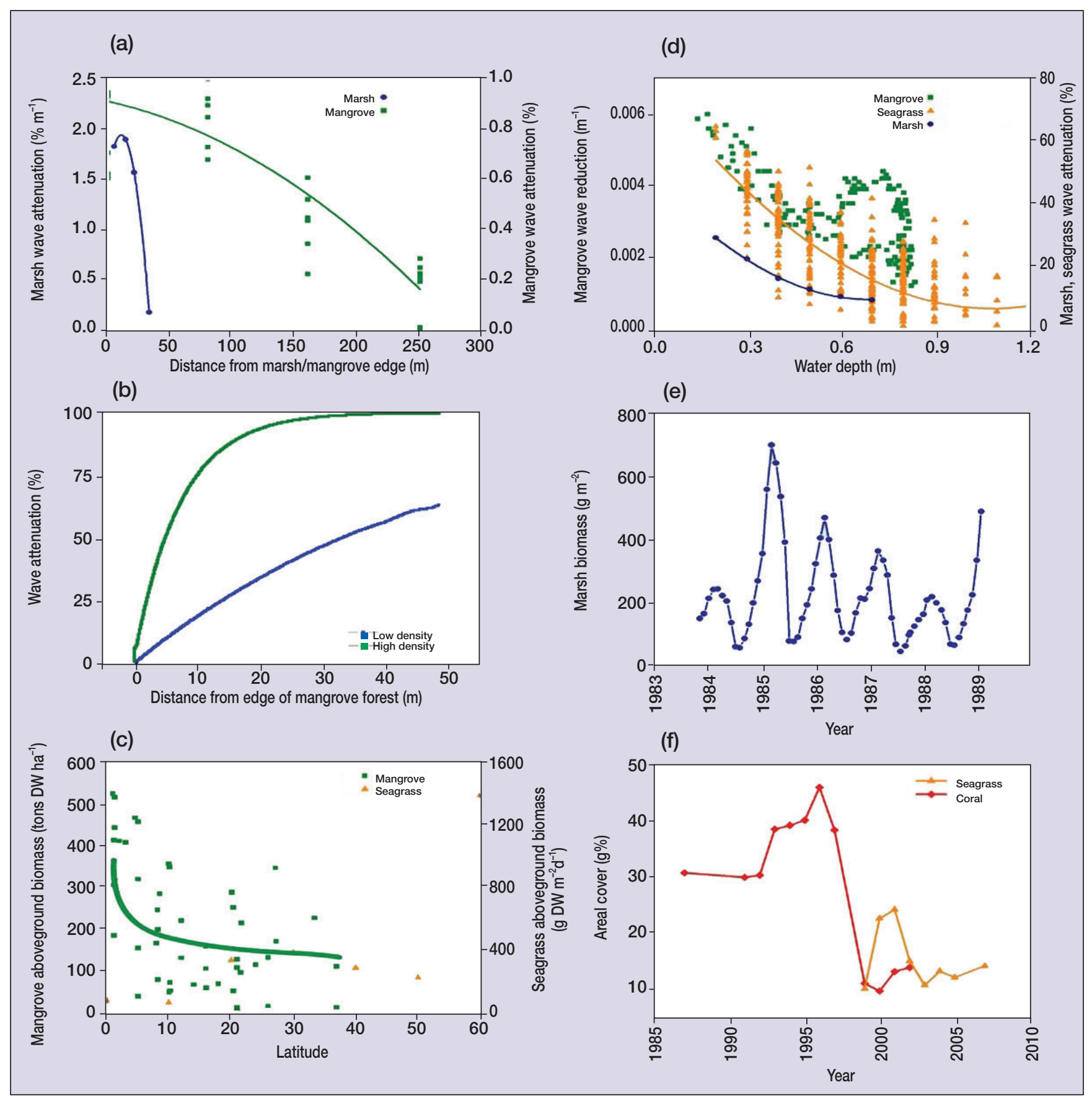

Figure 2. Examples of non-linearities in wave attenuation. Direct measurements of wave attenuation only exist for the smallest spatial (a; Massel et al. 1999; Moller 2006) and temporal (d; Mazda et al. 2006; Moller 2006; Chen et al. 2007) scales. Wave attenuation for different mangrove densities (b) has been modeled (Massel et al. 1999). Latitudinal wave attenuation (c) is estimated, based on the aboveground biomass of mangroves (Twilley et al. 1992) and seagrasses (Duarte and Chiscano 1991), ie obstructions to water flow. Wave attenuation over different seasons is also assumed to change with marsh aboveground biomass (e; Morris and Haskin 1990). Inter-annual variability in corals (modified from McClanahan et al. 2005) and seagrass (Merkel 2008) areal cover $(f)$ is used to estimate long-term trends in wave attenuation.

range of spatial scales, there is a wide range of non-linearity in the generation of this ecosystem function.

\section{Coastal protection varies over time}

Non-linearity in the provision of coastal protection as a result of wave attenuation can also be observed from the shortest (hours) to the longest (decadal) temporal scales. Dissipation of wave energy is a direct function of the percentage of the water column occupied by vegetation (Fonseca and Cahalan 1992); as a result, wave attenuation will depend on tidal level and height of biotic structures. For example, wave attenuation is highest for seagrasses when water levels are low and their biomass is 


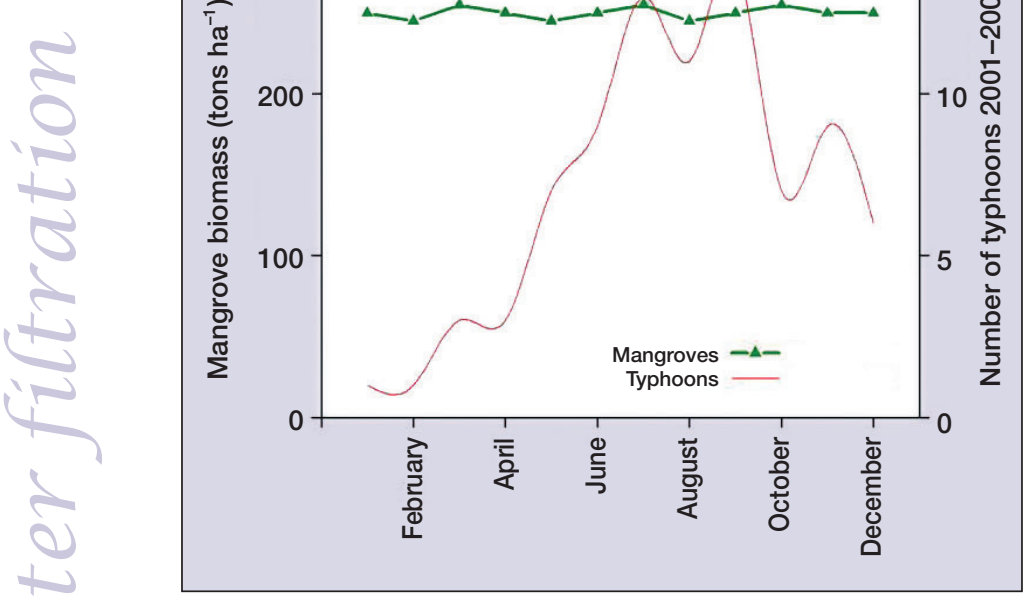

Figure 3. The timing of forcing events affects the value of ecosystem services. Biomass of coastal plant communities is highly variable/seasonal in (a) temperate areas, while in (b) tropical areas biomass is relatively constant. Maximum wave attenuation (ie maximum biomass) in seagrass (Zostera marina) beds in Korea does not coincide with the time of strongest winds. The value of this ecosystem function is therefore diminished. In contrast, biomass in a mangrove forest (Tam et al. 1995) is relatively constant over time. As a result, independent of the timing of storm events, a high level of coastal protection is provided throughout the year.

compressed into a smaller water column (Figure $2 \mathrm{~d}$ ). Wave attenuation in seagrasses, marshes, and mangroves decreases non-linearly as the tide rises (Figure 2d); however, when water reaches the leaves and branches in mangrove forests, wave attenuation increases again, as there are more "obstructions" to wave propagation (Figure 2d; Mazda et al. 2006; Quartel et al. 2007). Overall, coastal protection should be highest when the tide is low and the biomass of biotic structures is at its maximum. As such, the value of coastal protection is expected to change seasonally (Coops et al. 1996), especially in temperate areas (Figure 2e), where vegetation density can vary dramatically. Similarly, interannual variability in plant cover (Figure 2e, f) will affect the magnitude and value of coastal protection.

Coastal protection is also dependent on the timing of natural processes, such as storms, hurricanes, and tsunamis. Protection will be diminished if storms occur when plant biomass and/or density are low (Figure 3a). This is of particular importance in temperate regions, where seasonal fluctuations of biomass may be offset from the seasonal occurrence of storms. For example, biomass of the seagrass Zostera marina in Korea peaks in the summer (April-June), yet decreases in the fall (July-September; Kaldy and Lee 2007), when the strongest winds, and thus the biggest waves, occur (Figure 3a). In tropical areas, biomass of biotic structures tends to be less variable over time, and therefore provides more predictable coastal protection throughout the year. For instance, mangrove forests in southeast Asia, which have a relatively constant biomass throughout the year (Tam et al. 1995), provide relatively constant ecosystem services, independent of the typhoon season (Figure 3b).

\section{Coastal protection as a function of species and habitat quality}

Few studies have compared the wave attenuation functions of different species of mangroves, marsh plants, or seagrasses (Bouma et al. 2005). Using aboveground biomass as a proxy for wave attenuation, it seems reasonable to assume that different species have different effects on wave attenuation. The work that has been done shows that the highest wave attenuation by subtidal species occurs in communities that occupy the entire water column (Koch et al. 2006). Morphology and biomass distribution of biotic structures also have a major effect on wave attenuation (Massel et al. 1997). For instance, wave attenuation by the mangrove Sonneratia sp, which has large pneumatophores (aerial roots that protrude from the ground) exceeds that of Kandelia candel which does not produce pneumatophores (Mazda et al. 1997, 2006).

Habitat quality may also influence wave attenuation and add an extra level of complexity to valuation estimates of coastal protection. It makes sense that stressed organisms should have lower biomass and density, leading to lower wave attenuation (eg Massel et al. 1999). These stresses may be natural (eg the degree of flooding in marshes and mangroves contributes to plant size and zonation), but others are certainly anthropogenic (eg eutrophication causing the thinning or loss of seagrasses). Reef crest habitat degraded by bleaching, species turnover, waves, and bioerosion is physically smoother than intact habitat and provides less friction to dampen incoming waves (Sheppard et al. 2005). Healthy mangrove communities characterized by true mangrove genera, such as Rhizophora and Sonneratia, have been shown to suffer comparatively little typhoon-related damage as compared to 
degraded mangrove sites dominated by vegetative associates (Dahdouh-Guebas et al. 2005). The influence of habitat quality is an important but understudied aspect of non-linearity when evaluating the actual value of ecosystem services such as wave attenuation.

\section{- Cumulative effects of wave attenuation in coastal systems}

As discussed previously, coastal protection is a result of more than the sum of the wave attenuation provided by individual biotic structures; it is the cumulative effect imposed on waves by biotic and abiotic characteristics of the coastal zone (Barbier et al. 2008b; Feagin 2008). Although biotic structures appear to dampen most of the wave energy, local geomorphology and bathymetry also play a major role in wave dissipation (Komar 1998). The different species of plants found at various depths provide additional complexity (Quartel et al. 2007), as each biotic community has a different drag coefficient contributing to the attenuation of incoming waves.

Waves approaching a coastal area are first affected when they contact the sediment (Figure 4). This may be due to shoaling/shallowing of the area or a reef. The wave then propagates through seagrass beds (often several different species colonizing different depths), where it may be attenuated, depending on the fraction of the water column occupied by the vegetation (Fonseca and Cahalan 1992; Koch et al. 2006). An even less energetic wave then reaches the mangroves or marshes, where stiffer (ie woody) species are often three times more effective at attenuating waves (Bouma et al. 2005).

Temporal fluctuations in water level (ie tides and storm surges) further add to the complexity of wave attenuation processes (Figure 4). At low tide, when mangroves and marshes are fully exposed to air, only the available seagrasses contribute to wave attenuation (Koch and Gust 1999; Madsen et al. 2001). As waves move shoreward, out of the seagrass beds, shoaling may regenerate wave height (negative wave attenuation due to wave build up) until they reach the shore, where they break (ie 100\% attenuation).

\section{Valuation of non-linear ecosystem services}

The recent interest in valuing ecosystem services to more fully understand best management practices necessitates incorporation of the non-linear properties of these services over space and time, to more accurately represent their value. Here, we expand on a paper by Barbier et al. (2008a) that considers the non-linear properties of ecosystem services in mangroves by incorporating the effect of both plant species and tidal level on wave attenuation. We calculated the value of storm protection services of Sonneratia sp and Kandelia candel mangrove plantations in Vietnam (Mazda et al. 1997), using the methodology of Barbier et al. (2008a), which assumed that each square kilometer of mangroves deforested involved the equivalent loss of $100 \mathrm{~m}$ of mangroves inshore, along a $10-\mathrm{km}$ coastline.

Wave attenuation by the mangroves is based on data from the coast of Vietnam (Mazda et al. 1997, 2006; Wolanski 2007), where plantations of $K$ candel and Sonneratia sp have been created over a wide intertidal shoal, as a coastal defense against typhoon waves. The Kandelia candel plantation at the study site is $1.5 \mathrm{~km}$ wide (perpendicular to the coast) and $3 \mathrm{~km}$ long (parallel to the coast). Wave data were measured in situ at three locations: the offshore edge of the forest (no attenuation by the vegetation), $100 \mathrm{~m}$ inside the forest, and approximately $1000 \mathrm{~m}$ from the first sampling site. Observations were collected for each species at two tide levels: mid and high tides. In this system, wave attenuation, and thus the storm protection value, of Sonneratia sp exceeds that of $K$ candel, and both are non-linear (Figure 5a). The wave attenuation relationship for each species was then used to 


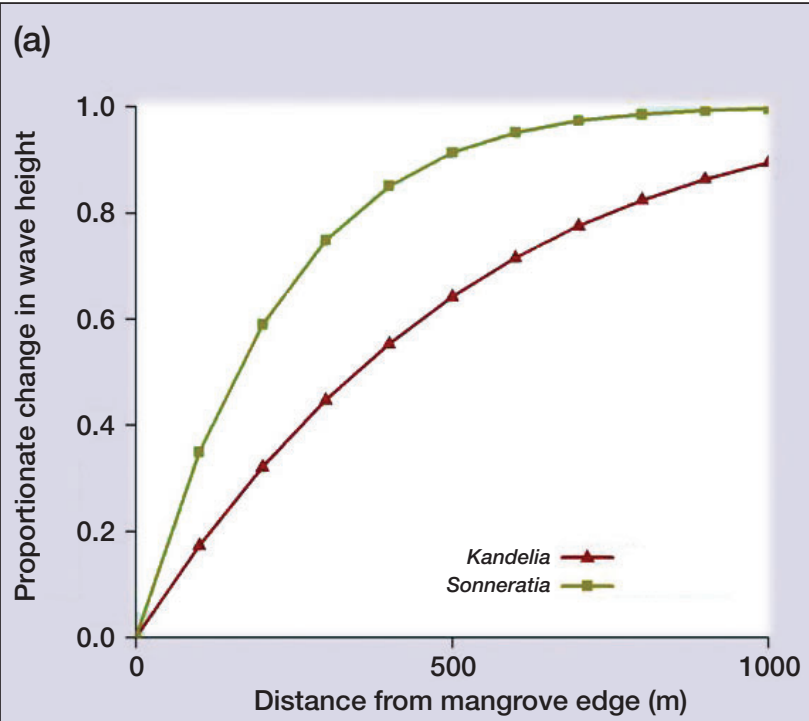

(c)

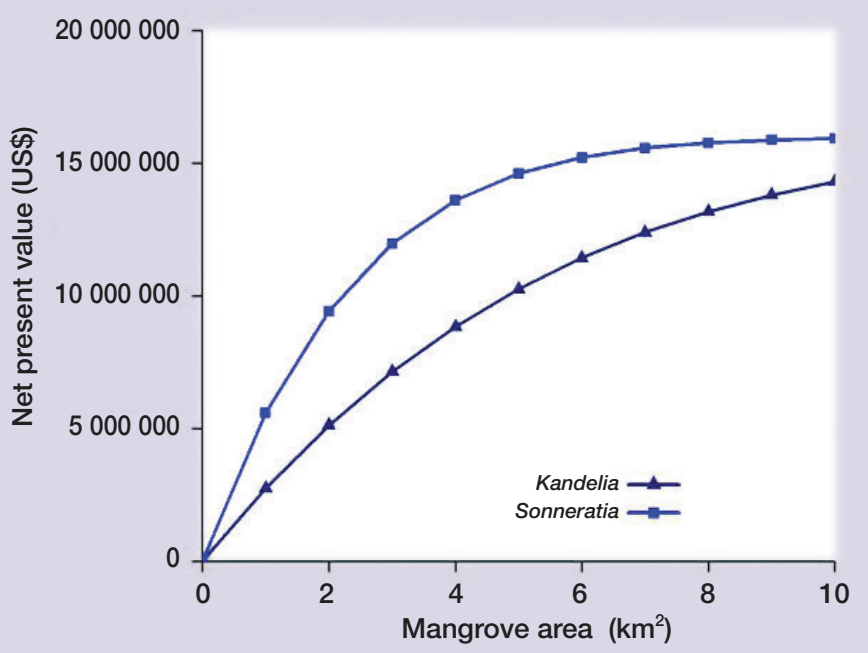

(b)

(d)
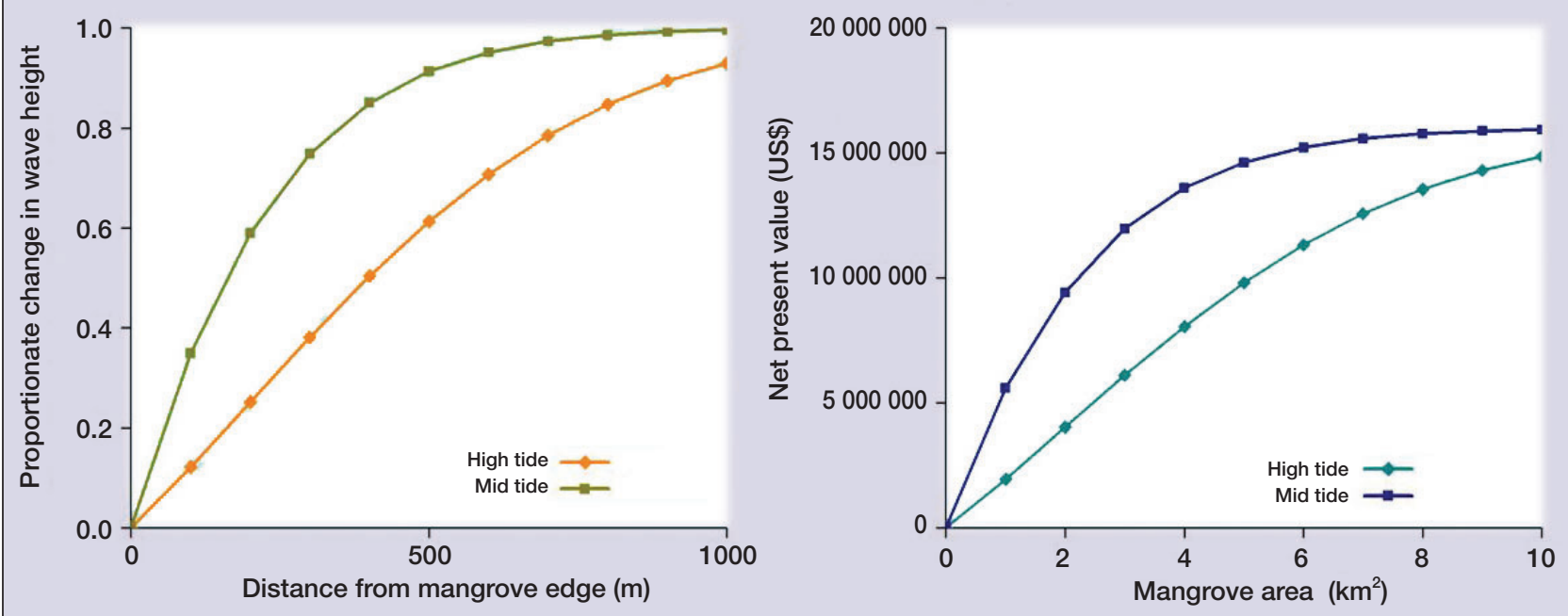

Figure 5. Wave attenuation by mangrove forests is a function of the distance from the seaward edge, and varies by (a) species and (b) tidal stage. See the supplementary online material accompanying Barbier et al. (2008a) for methods. As a result, the value of the ecosystem function provided by mangrove forests (net present value, 10\% discount rate, 1996 US\$) also varies by species composition (c) and tidal phase (d). The point estimate used for calculating the value of storm protection is the marginal value per $\mathrm{km}^{2}$ of \$1 599684 (net present value, 10\% discount rate, 1996 US\$) estimated in Barbier (2007). Wave attenuation for mangroves is based on data from Mazda et al. (1997, 2006) and Wolanski (2007) on the coast of Vietnam, where Kandelia candel and Sonneratia sp mangrove plantations have been created over a wide intertidal shoal, as a coastal defense against typhoon waves.

adjust the net present value $(10 \%$ discount rate, 1996 US\$) per square kilometer estimate for storm protection, following the method described in Barbier et al. (2008a); that is, it is assumed that mangrove deforestation occurs along a $10 \mathrm{~km}$ coastline (eg $1 \mathrm{~km}^{2}=100 \mathrm{~m} \times 10000 \mathrm{~m}$ ), and we adjusted the estimate used for calculating the value of storm protection per square kilometer accordingly. We plot the corresponding non-linear value for storm protection by species in Figure $5 \mathrm{~b}$. The difference between the two species in terms of storm protection value is at its maximum when mangrove area reaches $3 \mathrm{~km}^{2}$ (US\$11 972379 and US\$7 149601 for Sonneratia sp and $K$ candel, respectively). As mangrove area increases beyond $3 \mathrm{~km}^{2}$, the storm protection values of both species start to converge (Figure $5 \mathrm{~b}$ ). At the maximum mangrove area of $10 \mathrm{~km}^{2}$, the storm protection value is US\$15940572 for Sonneratia sp and US\$14 317997 for K candel.

If we consider the effect of tidal height, wave attenuation of Sonneratia sp is greater at mid tide than at high tide (Figure $5 \mathrm{c}$ ), so the storm protection value of this species is greater at this water level as well (Figure $5 \mathrm{~d}$; US\$11 972379 and US\$6 098261 for mid and high tide, respectively, at $3 \mathrm{~km}^{2}$ ). However, because of the non-linearity in this relationship, the difference declines as the mangrove area increases. At the maximum mangrove 
area of $10 \mathrm{~km}^{2}$, Sonneratia sp has a storm protection value of US\$15 940572 at mid tide and US\$14 866645 at high tide. Although not shown here, wave attenuation, and thus the storm protection value for $K$ candel, is always greater at mid tide as compared to high tide as well, but the difference is not as dramatic as for Sonneratia sp.

These data show the importance of tidal level, mangrove species, and forest area in the valuation process. If linearity had been assumed and only one point representing a certain species had been chosen, the values would have under- or overestimated the actual value of the service. These data also highlight the need to take non-linearities into account when making management decisions. For example, if only part of the $10-\mathrm{km}^{2}$ mangrove forest is to be restored $\left(<7 \mathrm{~km}^{2}\right)$, the highest coastal protection value would be provided by Sonneratia sp, but if an area larger than $10 \mathrm{~km}^{2}$ is to be restored, the advantages of planting Sonneratia sp instead of K candel are less clear and may depend on other ecosystem services provided by these two species.

\section{Management of coastal protection}

Managers of coastal systems seeking to sustain and enhance wave protection for local communities, and to take advantage of the effects described above, have a number of options available to them: conservation of existing conditions; restoration or rehabilitation of elements which have been lost or damaged; and structural engineering approaches. Each of these can involve both synergistic benefits and/or trade-offs among the various ecosystem services that coastal systems provide to local communities. The non-linearities in wave attenuation described above accentuate the complexity of coastal management decisions but, at the same time, provide a theoretical framework for the generation of a quantitative approach to the management decision-making process. The lack of acknowledgement of these non-linearities, as is often the case when only local, short-term data are available, can result in additional management problems. For example, managers may focus on the spatial extent of mangroves rather than on the density of trees in restoration and, consequently, not gain the full coastal protection they expected.

Conservation is a viable option for managers, where biotic structures currently provide wave attenuation benefits to coastal villages, but non-linearities need to be taken into account when determining the area to be preserved. A complete evaluation of multiple ecosystem services (eg Barbier et al. 2008a) can be used to justify conservation decisions and enable non-linearities in service provision to be considered in coastal planning. Where the wave attenuation provided by natural ecosystem components has been lost or impaired, restoration or rehabilitation can be justified by managers on the basis of before/after studies or comparisons between areas with and without biotic structures. The success of such efforts is influenced by elements of non-linearity in wave attenuation described above. Non-linear cumulative effects can also play a major role in coastal restoration. Key geomorphologic features or communities may be needed to either fully compensate for lost services, such as wave attenuation (Figure 4), or to facilitate the re-establishment of a full array of services. For example, in areas with high wave energy, a sill (submersed rocks forming a barrier), extensive shoals, or coral/oyster reefs may be essential for creating wave conditions suitable for less wavetolerant communities. If a key structure that reduces wave energy is lost, seagrasses, mangroves, or marshes are threatened and their ability to provide coastal protection may be diminished or lost altogether. Such is the case in Florida, where the loss of sand bars led to the disappearance of seagrasses (Lewis 2002) and in coastal Louisiana, where restoration of wave attenuating coastal marshes will require the rebuilding of substrate elevations to allow vegetation to recolonize the area.

For many coastal managers, structural engineering approaches, such as seawalls and bulkheads, provide the easiest and most dependable remedy to protect coastal property, villages, and cities from erosion associated with wave impacts. Breakwaters can simulate the wave attenuation function of natural communities by diminishing wave energy before it reaches the shore, while barriers further inland can directly protect coastal infrastructure. Indeed, in some areas, placing hard structures above the high water level to "hold the line" can be easier to implement than ecosystem-based solutions, as permitting requirements outside (or inland) of the "coastal zone" are less stringent (NRC 2007). However, engineered approaches rarely consider the indirect costs in terms of loss of other ecosystem services associated with loss of natural habitat. Thus, wave protection using engineered structures can result in conflict between various ecosystem services (ie wave protection or nutrient uptake), whereas conservation or restoration approaches can allow for synergies (ie wave protection and nutrient uptake). By considering spatial and temporal non-linearities in wave attenuation in EBM practices, better solutions may be found, errors may be minimized, and unnecessary or over-engineered wave attenuating structures may be avoided.

\section{Conclusions and recommendations}

Ecosystem functions such as wave attenuation not only have a specific value, but this value is also highly dynamic, changing over both space and time, usually in a non-linear way. The ecosystem service of coastal protection is also non-linear and dynamic. Although there are general commonalities in wave attenuation processes between plant communities (eg in Figure 2d), we show that there are many important factors, such as plant density and location, species, tidal regime, seasons, and latitude, that can also influence the patterns of non-linearity 
observed. As a result, temporal and spatial non-linearity, as well as cumulative effects in wave attenuation, must be accounted for, if we are to accurately estimate the value of coastal protection and incorporate it into management decisions. We are therefore calling for a new field in EBM, in which environmental management decisions are based on the quantification of non-linearities in ecosystem functions and services. To accomplish this goal, we recommend the following: (1) collection and/or synthesis of new and existing data on the functional characteristics of coastal habitats that provide important services to humans - that is, filling existing data gaps, especially with comparative studies; (2) analysis of data, to better understand patterns of non-linearity in space and time - dynamic ecological models may be needed to account for multiple non-linearities and cumulative effects (eg when an ecosystem function varies simultaneously over time and space); (3) testing of assumptions of linearity in the valuation of ecosystem services - as we have found for coastal protection, this assumption is false in most cases; (4) evaluation of the relevance of non-linearity at different spatial and temporal scales in ecosystem service valuation processes sensitivity analysis is critical; (5) incorporation of the value of ecosystem services into management decisions to maximize these services, to the largest extent possible; and (6) application of the methods used to elucidate the mechanisms controlling ecosystem functions to the nascent field of EBM. We suggest that the combination of dynamic ecological modeling, greater field-based testing of the functional relationships of ecosystem services, and economic valuation of those services will increase our ability to accurately value coastal ecosystems and, in turn, refine EBM practices. Collaboration between economists and ecologists is essential in this process; we call on economists to use existing dynamic models of coastal systems for future economic valuation and on ecologists to fill knowledge gaps regarding the functional characteristics of coastal habitats that provide ecosystem services. Given the dominance of non-linearity in the generation of coastal protection, we expect non-linearity to be the common functional relationship for many other ecosystem services as well.

\section{- Acknowledgements}

This work was conducted as a part of the Measuring ecological, economic, and social values of coastal habitats to inform ecosystem-based management of land-sea interfaces Working Group supported by the National Center for Ecological Analysis and Synthesis, a Center funded by NSF (\#DEB-0553768), the University of California, Santa Barbara, the State of California, and the David and Lucile Packard Foundation. Several colleagues kindly shared data: I Moller provided the data for marsh wave attenuation in Figure 2d, while J Kaldy and K Seoup made Figure 3a possible. K Merkal provided the seagrass data for Figure $2 \mathrm{f}$ and Gil Cintron provided mangrove aboveground biomass data. Symbols used in Figure 4 are courtesy of the Integration and Application Network (www.ian.umces.edu/symbols/), University of Maryland Center for Environmental Science. D Shafer provided insight from the seagrass and coastal engineering perspectives. This paper is dedicated to Prof Dr Walter Koch, who passed away on February 9, 2008, at the age of 82 . He was admired for reaching his stars and loved for helping others reach theirs.

\section{References}

Aburto-Oropeza O, Ezcurra E, Danemann G, et al. 2008. Mangroves in the Gulf of California increase fisheries yields. P Natl Acad Sci 105: 1056-50.

Barbier EB. 2007. Valuing ecosystem services as productive inputs. Econ Policy 22: 177-229.

Barbier EB, Koch EW, Silliman B, et al. 2008a. Coastal ecosystembased management with non-linear ecological functions and values. Science 319: 321-23.

Barbier EB, Koch EW, Silliman B, et al. 2008b. Vegetation's role in coastal protection: response. Science 320: 177.

Boer WF. 2007. Seagrass-sediment interactions, positive feedbacks and critical thresholds for occurrence: a review. Hydrobiologia 591: 5-24.

Bouma TJ, De Vries MB, Low E, et al. 2005. Trade-offs related to ecosystem engineering: a case study on stiffness of emerging macrophytes. Ecology 86: 2187-99.

Cain ML, Bowman WD, and Hacker SD. 2008. Ecology. Sunderland, MA: Sinauer Associates.

Chen SN, Sanford LP, Koch EW, et al. 2007. A nearshore model to investigate the effects of seagrass bed geometry on wave attenuation and suspended sediment transport. Estuaries 30: 296-310.

Coops H, Geilen N, Verheij HJ, et al. 1996. Interactions between waves, bank erosion and emergent vegetation: an experimental study in a wave tank. Aquat Bot 53: 187-98.

Dahdouh-Guebas F, Jayatissa LP, Di Nitto D, et al. 2005. How effective were mangroves as a defence against the recent tsunami? Curr Biol 15: 1337-38.

Dobson A, Lodge D, Alder J, et al. 2006. Habitat loss, trophic collapse, and the decline of ecosystem services. Ecology 87: $1915-24$.

Duarte CM and Chiscano CL. 1999. Seagrass biomass and production: a reassessment. Aquat Bot 65: 159-74.

Farnsworth E. 1998. Issues of spatial, taxonomic and temporal scale in delineating links between mangrove diversity and ecosystem function. Global Ecol Biogeogr 7: 15-25.

Feagin RA. 2008. Vegetation's role in coastal protection. Science 320: $176-77$.

Fonseca MS and Cahalan JA. 1992. A preliminary evaluation of wave attenuation by four species of seagrass. Estuar Coast Shelf S 35: 565-76.

Gacia E, Granata TC, and Duarte CM. 1999. An approach to measurement of particle flux and sediment retention within seagrass (Posidonia oceanica) meadows. Aquat Bot 65: 255-68.

Gaston K and Blackborn T. 2000. Pattern and process in macroecology. Oxford, UK: Blackwell Science.

Halpern BS, Walbridge S, Selkoe KA, et al. 2008. A global map of human impact on marine ecosystems. Science 319: 948-52.

Hein L, van Koppen K, de Groot RS, et al. 2006. Spatial scales, stakeholders and the valuation of ecosystem services. Ecol Econ 57: 209-28.

Kaldy JE and Lee KS. 2007. Factors controlling Zostera marina L growth in the eastern and western Pacific Ocean: comparisons between Korea and Oregon, USA. Aquat Bot 87: 116-26.

Koch EW and Gust G. 1999. Water flow in tide and wave domi- 
nated beds of the seagrass Thalassia testudinum. Mar Ecol-Prog Ser 184: 63-72.

Koch EW, Ackerman J, van Keulen M, et al. 2006. Fluid dynamics in seagrass ecology: from molecules to ecosystems. In: Larkum A, Orth R, and Duarte C (Eds). Seagrasses: biology, ecology and their conservation. Berlin, Germany: Springer-Verlag.

Komar PD. 1998. Wave erosion of a massive artificial coastal landslide. Earth Surf Proc Land 23: 415-28.

Komiyama A, Ong JE, and Poungparn S. 2008. Allometry, biomass, and productivity of mangrove forests: a review. Aquat Bot 89: 128-37.

Lewis III RR. 2002. The potential importance of the longshore bar system to the persistence and restoration of Tampa Bay seagrass meadows. In: Greening HS (Ed). Seagrass management: it's not just nutrients! St Petersburg, FL: Tampa Bay Estuary Program.

Madin JS and Connolly SR 2006. Ecological consequences of major hydrodynamic disturbances on coral reefs. Nature 444: 477-80.

Madsen JD, Chambers PA, James WF, et al. 2001. The interaction between water movement, sediment dynamics and submersed macrophytes. Hydrobiologia 444: 71-84.

Massel SR, Furukawa K, and Brinkman RM. 1999. Surface wave propagation in mangrove forests. Fluid Dyn Res 24: 219-49.

Mazda Y, Wolanski E, King B, et al. 1997. Drag force due to vegetation in mangrove swamps. Mangroves and Salt Marshes 1: 193-99.

Mazda Y, Magi M, Kurokawa YT, et al. 2006. Wave reduction in a mangrove forest dominated by Sonneratia sp. Wetlands Ecol Manage 14: 365-78.

McClanahan TR, Mwaguni S, and Muthiga NA. 2005. Management of the Kenyan coast. Ocean Coast Manage 48: 901-31.

Merkel K. 2008. Eelgrass habitat surveys for the Emeryville flats and Clipper Cove, Yerba Buena Island (October 1999-2005, and 2007). Sacramento, CA: California Department of Transportation.

Mitsch WJ and Gosselink JG. 1993. Wetlands. New York, NY: Van Nostrand Reinhold.

Moller I. 2006. Quantifying saltmarsh vegetation and its effect on wave height dissipation: results from a UK East coast saltmarsh. Estuar Coast Shelf 69: 337-51.

Morris JT and Haskin B. 1990. A 5-yr record of aerial primary production and stand characteristics of Spartina alterniflora. Ecology 71: 2209-17.

NRC (National Research Council). 2005. Valuing ecosystem services. Washington, DC: National Academy Press.
NRC (National Research Council). 2007. Mitigating shore erosion along sheltered coasts. Washington, DC: National Academy Press.

Orth RJ, Carruthers TJB, Dennison WC, et al. 2006. A global crisis for seagrass ecosystems. BioScience 56: 987-96.

Petersen JE, Kemp WM, Bartleson R, et al. 2003. Multiscale experiments in coastal ecology: improving realism and advancing theory. BioScience 53: 1181-97.

Quartel S, Ruessink BG, and Kroon A. 2007. Daily to seasonal cross-shore behaviour of quasi-persistent intertidal beach morphology. Earth Surf Proc Land 32: 1293-1307.

Sheppard C, Dixon DJ, Gourlay M, et al. 2005. Coral mortality increases wave energy reaching shores protected by reef flats: examples from the Seychelles. Estuar Coastal Shelf S 64: 223-34.

Silliman BR, van de Koppel J, Bertness MD, et al. 2005. Drought, snails and large-scale die-off of southern US salt marshes. Science 310: 1803-06.

Shuto N. 1987. The effectiveness and limit of tsunami control forests. Coast Eng Jap 30: 143-53.

Tam NFY, Wong YS, Lan CY, et al. 1995. Community structure and standing crop biomass of a mangrove forest in Futian Nature Reserve, Shenzhen, China. Hydrobiologia 295: 193-201.

Twilley RR, Chen RH, Hargis T. 1992. Carbon sinks in mangroves and their implications to carbon budget of tropical coastal ecosystems. Water Air Soil Poll 64: 265-88.

van Proosdij D, Davidson-Arnott RGD, and Ollerhead J. 2006. Controls on spatial patterns of sediment deposition across a macro-tidal salt marsh surface over single tidal cycles. Estuar Coast Shelf 69: 64-86.

Wolanski E 2007. Estuarine ecohydrology. New York, NY: Elsevier.

${ }^{5}$ CONICET - Instituto Argentino de Oceanografia y Departamento de Geología, Universidad Nacional del Sur, Bahía Blanca, Argentina; ${ }^{6}$ Department of Zoology, Oregon State University, Corvallis, OR; ${ }^{7}$ Environmental Science and Management, Portland State University, Portland, OR; ${ }^{8}$ Aquaculture Department, Southeast Asian Fisheries Development Center, Tigbauan, Philippines; ${ }^{9}$ Wildlife Conservation Society, Western Indian Ocean Project, Mombasa, Kenya; ${ }^{10}$ Department of Applied Economics, University of Minnesota St Paul, St Paul, MN; ${ }^{11}$ National Center for Ecological Analysis and Synthesis, University of California Santa Barbara, Santa Barbara, CA; ${ }^{12}$ ACTFR, James Cook University, Townsville, Australia

\title{
TAKE THIS JOURNAL TO YOUR LIBRARIAN, PLEASE
}

\section{Are you enjoying this issue of Frontiers?}

\author{
If your library had a subscription, colleagues and students could enjoy it too.
}

Please consider recommending Frontiers in Ecology and the Environment to your library (ISSN 1540-9295).

\section{Thank you for your support}

You can obtain a subscription to Frontiers in Ecology and the Environment by contacting ESA Headquarters (+1 2028338773 ), online at www.esa.org, or through your subscription agent. To request a free sample issue, call or email Eric Gordon (eric@esa.org). 